УДК 538.9

\title{
Magnetization of Two-dimensional Layered HTSCs with Defects
}

\author{
Anna N. Moroz* \\ Anastasiia N. Maksimova ${ }^{\dagger}$ \\ Vladimir A. Kashurnikov ${ }^{\ddagger}$ \\ Igor A. Rudnev ${ }^{\S}$
}

National Research Nuclear University (Moscow Engineering Physics Institute)

Kashirskoe shosse, 31, Moscow, 115409

Russia

Received 05.12.2016, received in revised form 20.05.2017, accepted 24.01.2018

Calculations of behaviour of magnetization of type-II superconductors in external magnetic fields have been made by using the Monte-Carlo method within the limits of the model of layered HTSC. Magnetization curves have been acquired for samples of the most common materials. The influence of concentration and geometry of defects on magnetization processes has been investigated. Residual magnetization dependency on the concentration of defects and characteristic lengths of superconductors has been estimated.

Keywords: HTSC, modeling, magnetization, pinning, Monte-Carlo method.

DOI: 10.17516/1997-1397-2018-11-3-313-316.

\section{Introduction}

Today there is a rather large number of different superconducting materials, that draw great attention. A lot of experimental and theoretical studies are being conducted on them. These materials have different properties and parameters and behave differently in magnetic fields at various temperatures [1-5].

The analytical solution of the problem of dynamics of processes occurring in superconductors requires a special approach. The Monte-Carlo method (MCM) seems the most appealing for taking all of the necessary parameters into account. This method was used in papers [6-7], however only one superconducting material $\left(\mathrm{Bi}_{2} \mathrm{Sr}_{2} \mathrm{CaCu}_{2} \mathrm{O}_{8}\right)$ was studied in them.

Because of this it seems quite interesting to perform some numerical investigations of other known superconductors with a chance of comparing them to one another. Thus, the aim of this paper is to calculate and investigate the dependencies of magnetization of different type-2 superconductors on temperature, external magnetic field and defect concentration.

\section{Computation model}

High-temperature type-2 superconductors are layered materials that, in a simple way, can be pictured as alternating superconductor planes, separated by areas unpenetrated by the magnetic

\footnotetext{
*moroz.anna@hotmail.com

†nastymaksimova@yandex.ru

‡vakashurnikov@mail.ru

§iarudnev@mephi.ru

(c) Siberian Federal University. All rights reserved
} 
field. At certain temperatures the correlation between vortices of adjacent planes of the superconductor disappears, and the whole system turns into a set of non-interacting superconducting layers, inside of which the penetrating parts of vortices look like flat pancakes that interact with each other [6-7]. In this case, we can confine ourselves to considering only one superconducting plane and think of the results as an averaged response of the whole system.

The Gibbs potential for a two-dimensional system of interacting vortices consists of their self-energies, the energies of their mutual interactions, and their interactions with the surface of the sample as well as transport current and defects.

\section{Results}

The presence or absence of defects in a sample can significantly change the form of magnetization curves. The pinned vortices stay on their defects even when the magnetic field drops down to zero and thus create residual magnetization.

In this paper, we obtained magnetization curves of six different superconducting materials that contained 200, 400, and 700 randomly distributed defects. Since the energy of a vortex is determined by the parameters of the superconductor, different materials with the same defect distribution behave differently in magnetic fields.

Fig. 1 shows magnetization curves of three different samples (LSCO, BSCCO, and FeAs). The LSCO sample demonstrated the highest residual magnetization. Due to a large value of $\lambda=250 \mathrm{~nm}$ and $\xi=3.2 \mathrm{~nm}$ its residual magnetization adds up to almost 200 Gs (in the case of 700 defects).

If we consider the defect distribution as approximately even, we can roughly estimate the average distance between defects for the given concentration. By the calculations performed it has been estimated that for each given sample the value of $\lambda$ should be no less than half of the estimated distance in order to provide residual magnetization (Tab. 1).

The magnesium diboride sample with $\lambda=50 \mathrm{~nm}, \xi=10 \mathrm{~nm}$ showed the worst pinning properties: the minimum number of defects that will provide effective pinning in a $25 \cdot 10^{6} \mathrm{~nm}^{2}$ sample for this material is approximately $2200-2500$ since in this case the average distance between defects will be about $100 \mathrm{~nm}$. Despite having a much bigger value of $\xi$, the MgB2 sample requires much more defects for effective pinning, than the LSCO sample.

Table 1. The calculated minimum allowable numbers of defects that provide residual magnetization in a $5.5 \mathrm{~nm}$ sample

\begin{tabular}{|l|c|c|c|c|c|c|c|l|l|}
\hline \multirow{2}{*}{} & \multicolumn{3}{|c|}{ FeAs } & \multicolumn{2}{c|}{ YBCO } & \multicolumn{2}{c|}{ MgB $_{2}$} & \multirow{2}{*}{ LSCO } & \multirow{2}{*}{ BSCCO } \\
\cline { 2 - 9 } & 1111 & 122 & 111 & $\lambda=120$ HM & $\lambda=140 \mathrm{HM}$ & $\lambda=50 \mathrm{HM}$ & $\lambda=140 \mathrm{HM}$ & & \\
\hline $\mathrm{N}_{\text {def }}$ & 200 & 200 & 50 & 1000 & 500 & 2500 & 400 & 150 & 200 \\
\hline
\end{tabular}

\section{Conclusion}

9 samples were calculated using the Monte-Carlo method within the model of two-dimensional layered HTSC. All samples accord to the real known superconducting materials. Their similarities and differences have been determined. Magnetization curves for the mentioned samples with and without defects have been acquired. We have compared the samples and determined materials with the best and worst pinning properties. We have shown that the effectiveness of pinning 
in materials with defects depends on the concentration of defects as well as the characteristic lengths $\lambda$ and $\xi$ of the superconductor itself.

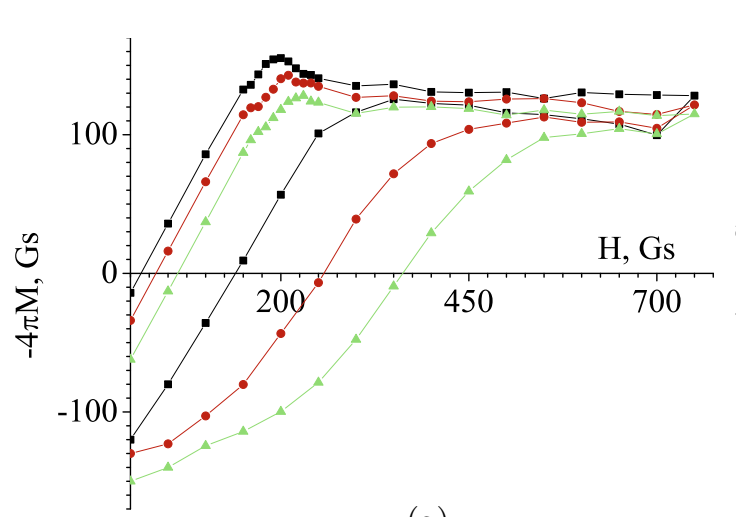

(a)

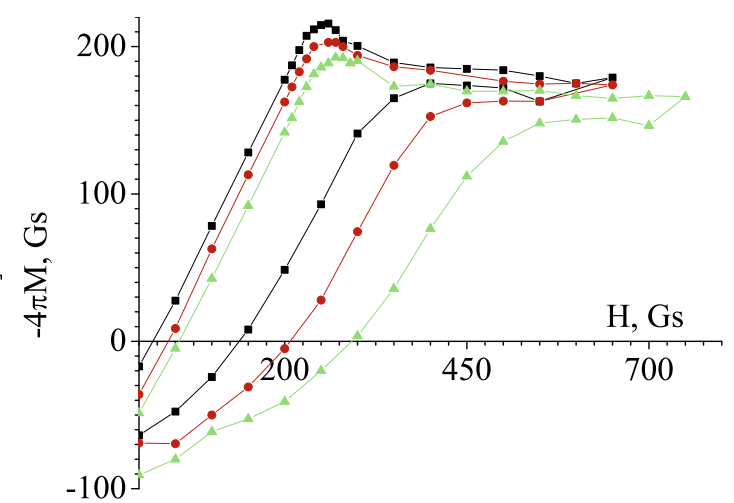

(b)

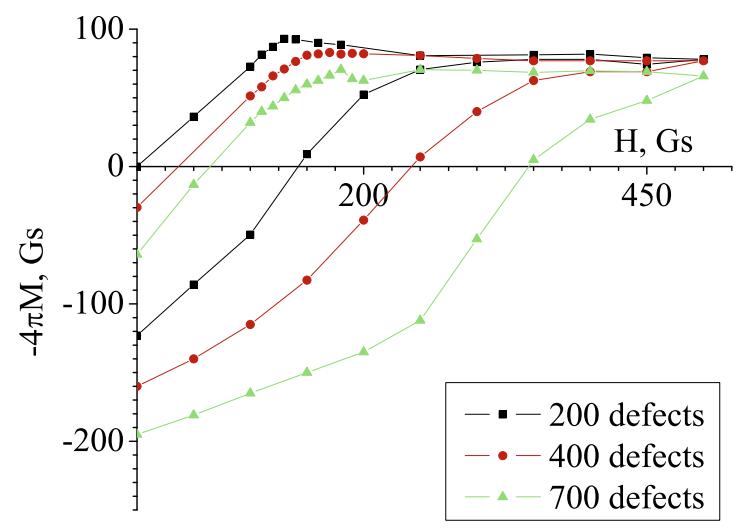

(c)

Fig. 1. Magnetization curves of superconducting materials: (a) FeAs 122; (b) BSCCO; (c) LSCO Research was done with the financial support of RFBR (grant no. 15-02-02764).

\section{References}

[1] I.Palecci et al., Upper critical fields and critical current densities of Fe-based superconductors as compared to those of other technical superconductors, Physica C: Supercond., 482(2012), $68-73$.

[2] S.Senoussi et al., The anisotropy of the irreversible magnetizations of $\mathrm{YBCO}$ and $\mathrm{LaSrCuO}$, Physica C: Supercond. and its App., 211(1993), 288-298.

[3] H.Yamasaki, A.Rastogi, A.Sawa, Hysteresis losses in thick YBCO films: a linear componential analysis of magnetization in nearly parallel magnetic fields, Cryogenics, 41(2001), $69-75$.

[4] Amish G.Joshi, C.G.S. Pillai, P.Raj, S.K.Malik, Magnetization studies on superconducting MgB2-lower and upper critical fields and critical current density, Solid state communications, 118(2001), 445-448. 
[5] G.Q.Yuan et al., Pinning effects and magnetization hysteresis loops in $\mathrm{MgB}_{2}$, Physica C: Supercond., 386(2003), 616-620.

[6] M.E.Gracheva, V.A.Kashurnikov, I.A.Rudnev, Monte-Carlo simulation of the two-dimensional vortex lattice melting in high-temperature superconductors with defects, Phys. LowDim. Struct., 8(1997), no. 9, 125-134.

[7] V.A.Kashurnikov, I.A.Rudnev, M.V.Zubin, Magnetization of two-dimensional superconductors with defects, JETP, 121(2002), no. 2, 442-452 (in Russian).

\section{Перемагничивание двумерных слоистых ВТСП с примесями}

\section{Анна Н. Мороз \\ Анастасия Н. Максимова \\ Владимир А. Кашурников \\ Игорь А.Руднев}

Кафедра физики твердого тела и наносистем (№70)

Национальный Исследовательский Ядерный Университет "МИФИ"

Каширское шоссе, 31, Москва, 115409

Россия

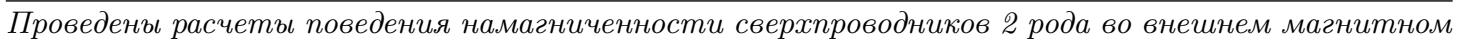
поле методом Монте-Карло в рамках модели слоистого ВТСП. Получены кривые намагниченности образцов наиболее известных сверхпроводящих материалов. Исследовано влияние кониентрации и конфигурации дефектов на процессы перемагничивания. Оценена зависимость величинь остаточной намагниченности от концентрации дефектов и характерных длин сверхпроводника.

Ключевые слова: ВТСП, моделирование, намагниченность, пиннинг, метод Монте-Карло. 